\title{
Improvement of quality by using an integrated management system of construction processes
}

\author{
Andrzej Sobczyk ${ }^{I^{*}}$, Janusz Pobędza ${ }^{l}$, and Małgorzata Sobczyk ${ }^{2}$ \\ ${ }^{1}$ Cracow University of Technology, Mech. Eng. Department, Al. Jana Pawla II 37, 31-864 Poland \\ ${ }^{2}$ M.Sc. Dip. Arch., BIM Specialist, London, UK
}

\begin{abstract}
The subject of the article is the concept of an innovative integrated construction management process connecting Building Information Modelling (BIM) and construction equipment with unique control systems. It would require developing an advanced software application allowing data exchange and keeping track of costconsumption, efficiency, use of building materials, as well as many other essential parameters, which would facilitate the improvement of quality of the technological process of construction works.
\end{abstract}

\section{Introduction}

The basic features of the proposed technology would be the introduction of an innovative system of managing construction works with organizational support, highly automated construction equipment and an IT system based on the integration of technical, organizational and economic information. Due to the dispersed nature of activities, starting from designing tasks to selection of materials to technology and related equipment, an IT system will be developed to enable remote integration of process elements and data exchange in real time as well as to monitor the schedule and quality of works on site. The BIM process has been used for planning, designing, implementation and operation so as to develop or utilize materials after renovation or demolition of a worn-out building (Fig.1). So far this management process has not been widely used in construction of machines for positioning, monitoring or machine management $[1,5]$. Therefore, the integration of the BIM process [2] will be an integral and necessary activity of this proposal.

In order to obtain high quality and efficiency of construction works in the same or even shorter time of the cycle, it would be essential to establish, as part of the development of this system, a research and development and training centre for the management staff, as well as for operators of the machines equipped with advanced information technologies and traffic control systems.

One of the examples of promising systems already in use worldwide is Machine Control System developed by TRIMBLE. Primary benefits of this solution include:

- Increased efficiency

- The accuracy of performing tasks in 3D environment and BIM process

- Savings in the use of building materials

- Savings in operation by reducing the number of hours to perform a specific task

- Increased reliability of machines

- Improvement of ergonomics of the machine operators' work

- The possibility of ongoing monitoring, management and possible adjustment of the technological process.

\footnotetext{
${ }^{*}$ Corresponding author: andrzej.sobczyk@mech.pk.edu.pl
} 


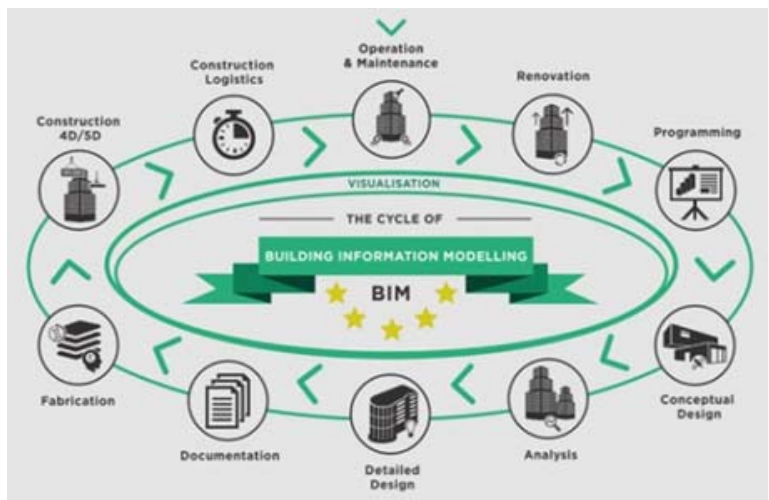

Fig. 1. BIM process structure used in civil engineering construction [2].

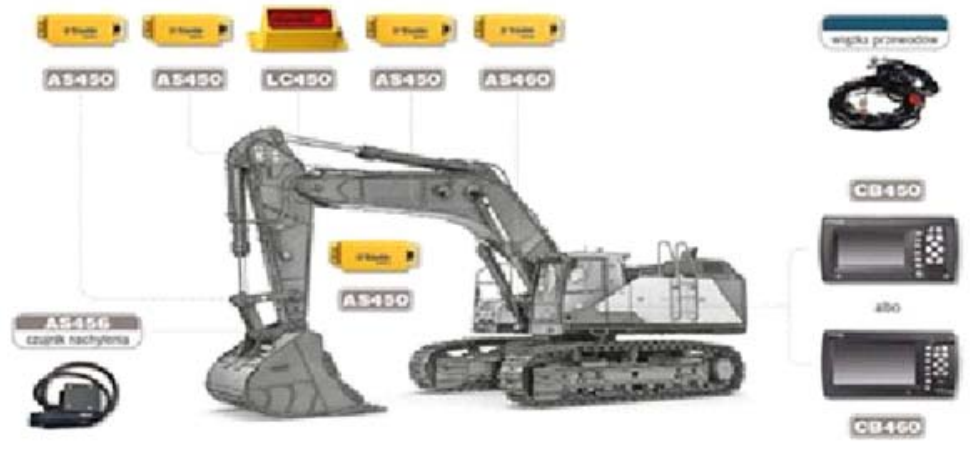

Fig. 2. An example of excavator with control-measuring equipment as part of work management system [3].

An additional reason for the application is the offer of SITECH Ltd, which is a licensed representative for Poland of the TRIMBLE EARTHWORKS 3D system, including its latest components, such as: Flexible Valve Driver with LED Status, The TD520 10" Touch Display, Joystick Remote Switch, GS520 Inertial Measurement Unit, The EC520 Electronic Controller, CAN interfaced I/Expansion module, The CI510. The AA510 is a CAN interfaced and configurable audible alarm. This module will also reduce the time required to perform individual construction works and minimize the costs of the business activity. Real estate site management will enable accurate planning of earthworks performed by excavators and other heavy mechanical equipment in real time. On-going planning of works on the construction site will allow for an increase of the efficiency of construction works and will contribute to the optimization of operations. While in use, the system will enable obtaining highly precise observational data for exchange.

\section{Highly precise position data project}

Currently, construction processes often rely on rented GPS receivers as base stations that give corrections after obtaining data in by radio transmission. The stations are also rented and then adjusted using Internet connection and radio wave combined. The services are provided only locally and the range of services included only cover only limited areas. The corrections are only corrections from a single reference station and are characterized by a decrease in accuracy, proportional to the distance from that station. The proposed solution to be implemented on the basis of innovative technology available on the international 
market will enable the provision of services in a much wider area - hundreds of square kilometres - by processing and sharing collected satellite information in real time. As it was mentioned previously, information processing was not carried out accurately by radio. Once received by the customer, the data was not updated in real time, as using the satellite signal was not possible to integrate. VRS3Net Plus innovative system software solutions will allow you to generate RTK corrections in real-time for any point inside the network area with the highest and equal accuracy, which has not been possible so far (the innovation on the international market). Until now, the accuracy of the point determination dropped in direct proportion to the distance from the reference station. For static measurements (determination of accuracy with increased accuracy), the user was required to have at least 3 receivers, at the same time observe at least two points with known coordinates and one point determined for a period of at least 1 hour. Observational data was transferred to the headquarters and it was subjected to analysis and technical processing. Only after these activities, processed data could be made available to recipients. Currently, the registered user of the system may have only one GNSS receiver and observe several minutes of data over the designated point and obtain a position of the point with a degree of precision not lower than $1 \mathrm{~cm}$ even in a few / several minutes after the measurement.

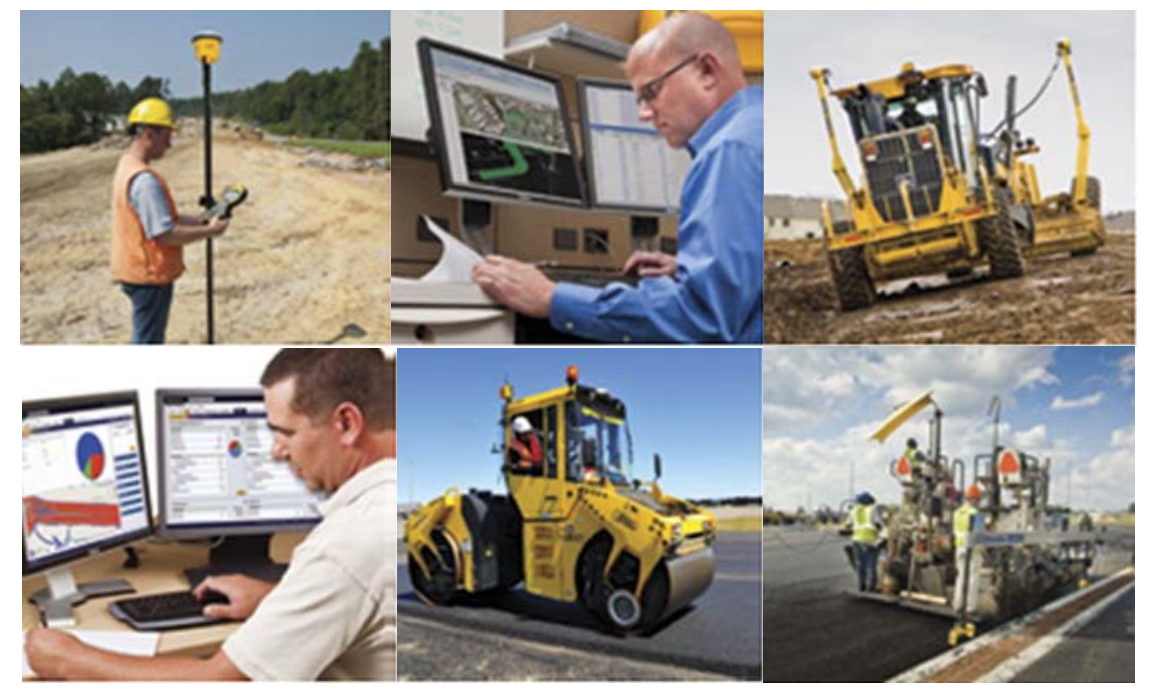

Fig. 3. Selected pictures illustrating application of Trimble equipment and software in cycles of field geo-work, design construction, earth moving and paving works and analysis of road construction processes [4].

The implementation of the project will allow users to provide satellite information on a regular basis, thanks to which they will be able to determine their position in the field clearly and without delay, which is an innovation on the international market. This information will be available to download from the website of the system from the tab reserved for registered customers. The data obtained through the reference station system will be passed on-line to users thanks to multiple systems sharing the produced results as well as online customer service. An innovative solution, in this case, will be the use of a multi-track system for sharing measurement data. Until now, users have been forced to be content with information obtained only via radio, which due to frequent disruptions and a limited range of waves significantly impeded the effective acquisition of coordinates of points in space. Thanks to the implementation of the proposed methodology, the basic data transmission system will be the Internet, whereas the radio system will be only complementary (in areas with limited GPRS coverage). 
The investment plan assumed the purchase and implementation of a technological solution that has been used in the world for a period not longer than 3 years. In particular, the latest components of the Earthwork system in earthworks are used in the world for no longer than one year. Detailed justification for the purchase and use of equipment and technology could be made after receiving introductory data of the particular project.

The reason for the application is the lack of comprehensive solutions for the implementation of construction tasks in the country, especially in the field of road infrastructure. The proposed concept suggests implementing the most modern equipment available on the market, both machines and electro-informatics equipment for geodetic equipment connected systemically with precise machine movement control systems. Such an approach, with the help of an information system that is part of the project, integrates and allows effective design of works, selection of necessary materials and hardware resources, technologies, management and supervision. The system proposed for implementation will also ensure a high level of quality while reducing construction costs through the optimal use of materials and precise work of construction machines, as well as shortening the time of implementation and thus reducing costs. It should also be added that the implementation of this integrated on-line construction management system - in road engineering or similar infrastructure - will prevent many mistakes at the implementation stage. Additionally, the applied IT and control systems will increase employee safety, which will reduce failure rates and damage to machines thanks to modules controlling their work parameters, independent even from the operator, thus eliminating inevitable human errors in the realities of the construction site.

\section{Conclusion}

To sum up, it is worth emphasising that machines equipped with the Control System described above prove that the system may be considered to be highly innovative. This is an integrated system which has not been used so far in Poland in machine construction in terms of not only positioning but also monitoring and management of machines, using advanced software that allows to keep track of cost-consumption, efficiency, consumption and material supplies and other interesting parameters of the technological process of construction works.

This high precision positioning system may be also very interesting for other application like e.g. precise positioning of the ground plant location in a biotechnology investigations $[6,7]$. Regardless, such system may be useful for creating of local mappings with support of a photogrammetry and an image analysis [8, 9], and an additional supporting system for an non-parametric uncertainty estimation [10-12]. The ability to obtain precise position records and appropriate control is very valuable during field testing in engineering research, both machine $[13,14]$ and materials science [15-23]. It is obvious that such RTK GPS utilizing system will have a great impact on a structure and capabilities of management systems in any domain where it will be applied [24-29].

\section{References}

1. A. Gawlik, A. Sobczyk, P. Walczak, Technical Trans., 113(5), 13 (2016)

2. BIM Object Cloud Solution. http://www.bim.com

3. Sitech Polska. http://www.sitech.pl

4. Trimble Inc., 935 Stewart Drive, Sunnyvale, CA 94085

5. P. Kucybała, J. Pobędza, A. Sobczyk, J. KONES 21(2), 169 (2014) 
6. E. Skrzypczak-Pietraszek, A. Hensel, Pharmazie, 55, 768 (2000)

7. E. Skrzypczak-Pietraszek, I. Kwiecien, A. Goldyn, J. Pietraszek, Phytochem. Lett., 20, 443 (2017)

8. A. Gadek-Moszczak, Image Anal. Stereol., 36, 151 (2017)

9. A. Gadek-Moszczak, Image Anal. Stereol., 36, 207 (2017)

10. J. Pietraszek, A. Gadek-Moszczak, Solid State Phenom., 197, 162 (2013)

11. J. Pietraszek, A. Gądek-Moszczak, T. Torunski, Adv. Mat. Res.-Switz,. 874, 139 (2014)

12. J. Pietraszek, E. Skrzypczak-Pietraszek, Adv. Mat. Res.-Switz. 874, 151 (2014)

13. M.S. Kozien, J. Theor. Appl. Mech., 47, 411 (2009)

14. J. Selejdak, R. Ulewicz, M. Ingaldi, Proc. 23rd International Conference on Metallurgy and Materials, (Brno, Czech Republic, 2014)

15. T. Pieczonka, J. Kazior, A. Tiziani, A. Molinari, J. Mater. Process. Technol., 64, 327 (1997)

16. M. Ulewicz, U. Lesinska, M. Bochenska, Physicochem. Probl. Mi., 44, 245 (2010)

17. M. Ulewicz, E. Radzyminska-Lenarcik, Physicochem. Probl. Mi., 46, 119 (2011)

18. N. Radek, J. Pietraszek, B. Antoszewski, Adv. Mat. Res.-Switz., 874, 29 (2014)

19. T. Lipinski, A. Wach, Proc. $23^{\text {rd }}$ Int. Conf. on Metallurgy and Materials - METAL, (Brno, 2014)

20. D. Klimecka-Tatar, S. Borkowski, P. Sygut, Arch. Metall. Mater., 60, 735 (2015)

21. D. Klimecka-Tatar, G. Pawlowska, M. Sozanska, Arch. Metall. Mater., 60, 153 (2015)

22. R. Dwornicka, N. Radek, M. Krawczyk, P. Osocha, J. Pobedza, Proc. $26^{\text {th }}$ Int. Conf. on Metallurgy. and Materials - METAL, (Brno, Czech Republic, 2017)

23. A. Szczotok, J. Nawrocki, J. Pietraszek, Arch. Metall. Mater., 62, 587 (2017)

24. Kozien, E., Proc. 20th Int. Sci. Conf. on Economic and Social Dev. (ESD), (Prague, Czech Republic, 2017)

25. Kozien, E., Kozien, A., Proc. 23th Int. Sci. Conf. on Economic and Social Dev. (ESD), (Madrid, Spain, 2017)

26. A. Pacana, R. Ulewicz, Polish J. Environ. Studies, 16, 165 (2017)

27. Kozien, E., Kozien, M.S., Proc. 26th Int. Sci. Conf. on Economic and Social Dev. - Building Resilient Society (ESD), (Zagreb, Croatia, 2017)

28. Kozien, E., Kozien, A., Proc. 26th Int. Sci. Conf. on Economic and Social Dev. - Building Resilient Society (ESD), (Zagreb, Croatia, 2017)

29. E. Kozień, Proc. $31^{\text {st }}$ Int. Sci. Conf. on Economic and Social Dev. - Legal Challenges of Modern World (ESD), (Split, Croatia, 2018) 